\title{
Anti-crack calculation and engineering case of composite cement-soil pile wall

\author{
Huaifeng Tong ${ }^{\mathrm{a}}$, Xiaoqiang Wang ${ }^{\mathrm{b}}$
}

School of Civil Engineering, Luoyang Institute of Science and Technology , Luoyang 471023, P.R.China

atonghuaifeng@163.com, ’wangxq08@163.com

Keywords: Composite pile wall, cement-soil, anti-crack calculation, engineering case.

Abstract. The compound pile wall is a new supporting structure type. It has strong ability to reduce the pressure of water and soil. Its stiffness is between that of gravity retaining walls and cantilever-retaining pile wall. The stress of the front pile is affected by the moment of the wall, the concrete stiffness of the top of the wall, the soil settlement and resistance behind the wall, the speed of soil excavation of the front wall, the difference of water levels and the speed drops in front of and behind the wall. Based on the analysis of the above factors and project examples, the theoretical calculation and control problem of the crack about the front cement-soil wall were discussed.

\section{Introduction}

Brief Introduction to Composite Pile Wall Supporting Structure System. The composition of the cement soil pile wall waterproof curtain wall and $\mathrm{N}$ rows of small vertical pile vertical composite type pile wall, sometimes through concrete capping plate is connected, with water stopping and supporting the dual effect of the technology of the new-type supporting supporting technology, typical structures as shown in Figure 1 and Figure 2.

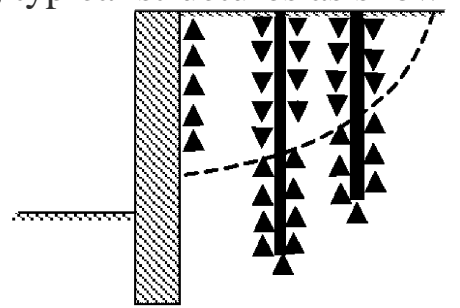

Fig.1 Compound pile wall ( I )

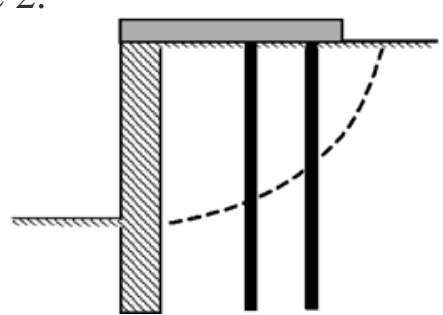

Fig.2 Compound pile wall ( II )

Cement soil pile wall: by double row soil cement pile, the wall thickness is $900 \sim 1000 \mathrm{~mm}$. small piles: as "no sand concrete small piles" or "mini piles, root piles", the emphasis is on "the earth between piles and soil".

Supporting Structure Calculation Model. Considering the weight loss of the rear side of the wall and the small pile, the pile wall is used to calculate the model. The model also considers the vertical weight loss and horizontal sliding action of the supporting piles. Composite pile wall as a whole, according to the traditional continuous wall calculation. This model can account for the top concrete plate and the front wall and the rear of the cement soil pile of small rigid connection, can effectively transfer moment.

\section{Anti Cracking Calculation of Front Wall of Supporting Structure}

Internal Force Calculation Method. The calculation of the strength of the front wall of the composite pile wall is an important step in the design and calculation of composite pile wall, and it is also a difficult point in the design and calculation. In this paper, we consider the factors and the calculation theory of the design calculation, and verify the correctness of the model by checking calculation. Considering the weight loss of a small pile, the soil is excavated to a depth, the vertical force difference between inside and outside soil of the front wall: 


$$
\begin{aligned}
& \Delta w=\gamma h\left(B_{1}+\frac{B_{2}}{2}\right)-\left(H \pi d_{0} \gamma_{G}\right) / 1.6 \\
& \sigma_{t}=\frac{12 M}{B_{0}^{2}}=\frac{6 \Delta w}{B_{0}} \\
& 0.1 f_{c u} \geq \sigma_{t} \Rightarrow f_{c u}=\frac{0.6 \Delta w}{B_{0}}
\end{aligned}
$$
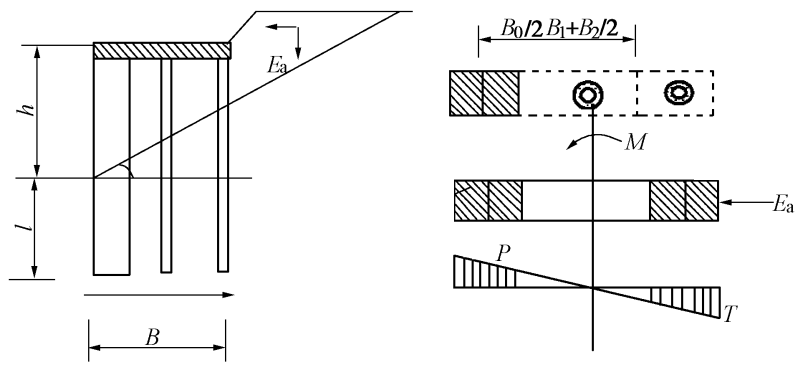

Fig. 3 Calculated diagram of moment of front wall

Main Factors Affecting the Cracking of the Front Wall. The influence of soft soil layer shown in Figure 4, For weak soil, when the groundwater level is high, the soil pressure is larger, the whole pile soil is poor, the pile body strength is generally lower, the compression deformation of the soil is larger. When the precipitation, the excavation speed faster, precipitation and excavation with poor, before and after the wall settlement may be inconsistent, will cause wall of cement soil piles of rear side resistance difference is larger, so the pile wall formed by precipitation and excavation of the additional moment(shown in Figure 5).

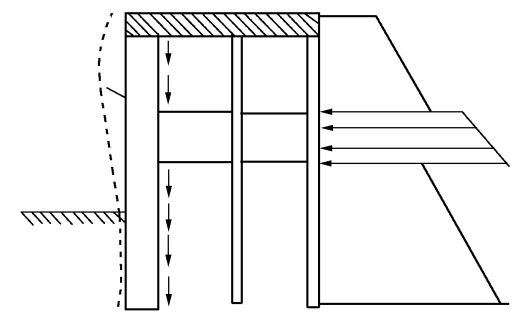

Fig. 4 The distribution of side resistance behind wall

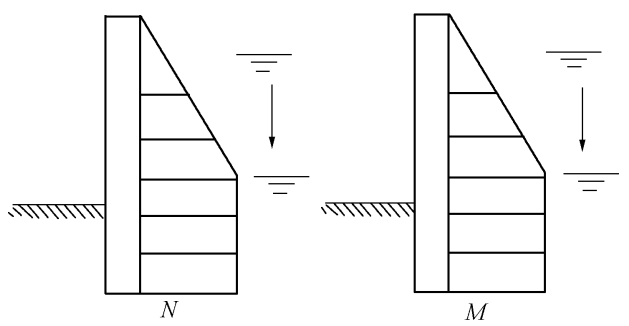

Fig. 5 The distribution of axial force and moment of pile wall

The influence of roof rigidity: the roof stiffness can be fully transmitted moment, the front wall does not produce earth pressure caused by the moment, at this time the front wall has a larger pressure stress. But when the stiffness of the concrete roof is insufficient or when the front and rear wall is not connected, negative bending moment will be generated in the front wall.

The unfavorable influence of the bearing capacity of the foundation under the wall on the crack resistance of the front wall: the bearing capacity of the foundation under the wall causes the increase of the rear side of the wall.

The effect of horizontal displacement of supporting structure on crack resistance of front wall: when the displacement of the continuous plate is larger, the inclined crack is generated at the 
bottom of the wall. The main reason is that the angle of the end wall is the biggest and the torque is large. Therefore, the supporting structure can not produce a large horizontal displacement, which is also applied to the pile anchor support system.

Influence factors and control measures of the quality of the front wall cement soil pile wall, related to the nature of the construction process and the soil itself, the general use of reinforced layer jet concrete cracking control and development of cracks, will not repeat them here.

In addition, the soil is poor, and the spacing of small piles is larger (greater than 6D $\sim 8 D$ ). The soil is poor, and the former wall cement soil may also form the moment of the thickness of the soil layer.

Above is the possible factors that need to be considered in the calculation of the cracking of the front wall of the wall, and the degree of its comprehensive effect or interaction is controllable.

\section{Engineering Case}

Engineering Survey. The main building covers an area of $32.4 \mathrm{~m} \times 32.4 \mathrm{~m}$, Above ground level 30 , height $120 \mathrm{~m}$, underground 2 , the frame core tube structure, pile raft foundation, buried deep 10 $\mathrm{m}$, local depth $11 \mathrm{~m}$. Engineering is in the typical soft soil area of Eastern Zhengzhou. The supporting structure of foundation pit is a composite pile wall technology, and precipitation is used in deep well precipitation.

Description of Cracking of Cement Soil Pile Wall. October 52004 on-site support structure construction, October 28, complete supporting structure construction, November 28, beginning of rainfall, December 3, began excavation construction. In the evening of December 13 2004, the northeast corner and the southwest corner of the excavation to the design elevation, an excavation depth of $4 \mathrm{~m}$, December 14, deformation of $10 \mathrm{~mm}$, December 15, deformation of $5 \mathrm{~mm}$, December 16, 17, tends to be stable. December 15 found that deep $6 \mathrm{~m}$ cement soil pile wall to crack, December16, 17, a close inspection found that the natural surface of the following deep 6 8m range are micro cracks, the maximum width of $3 \mathrm{~mm}$.

Have a side because of the depth of excavation exceeds the design depth, and continuous super dig wall and serious flooding accident, when the horizontal displacement of $160 \mathrm{~mm}$, resulting in the edge was splayed inclined cracks. The maximum horizontal displacement of the wall is $270 \mathrm{~mm}$.

Anti-crack Checking Calculation. According to the calculation of the whole gravity retaining wall, the tensile and compressive strength of the cement wall are considered, respectively.

Earth pressure calculation:

$$
\begin{aligned}
E_{a} & =\frac{W-C(H-B \tan \alpha)}{\tan \phi \sin \alpha+\cos \alpha} \sin \alpha(1-\tan \phi \sin \alpha-\tan \phi \cos \alpha)-C(H-B \tan \alpha)(\sin \alpha+\cos \alpha) \\
& =143.2 \mathrm{kN}
\end{aligned}
$$

The maximum additional negative bending moment caused by small piles and precipitation is generated at $7.1 \mathrm{~m}$ under the natural ground, the size is:

$$
M^{-}=\frac{\pi d q_{s i}\left(l_{2}-l_{02}\right) \times 2.95}{2 \times 1.2}+q_{s i} h_{i} \frac{2.95}{2}=170+418.9=588.9 \mathrm{kN} \times \mathrm{m}
$$

Calculation of the maximum positive moment produced by earth pressure:

$$
M^{+}=143.2 \times 5.4=773.3 \mathrm{kN} \times \mathrm{m} \text { 。 }
$$

Tension calculation of cement-soil wall By formula:

$$
\begin{aligned}
& \frac{M}{W}-\gamma_{\mathrm{cs}} z-\frac{q_{\mathrm{si}} h_{i}}{2.95}-\frac{\pi d q_{\mathrm{si}}\left(l_{2}-l_{02}\right)}{1.2 \times 2.95} \leq 0.06 f_{\mathrm{cs}} \\
& \frac{M^{-}}{\frac{1}{6} \times 1 \times 2.95^{2}}-22 \times 7.1-\frac{40 \times 7.1}{2.95}-\frac{3.14 \times 0.15 \times 5.65 \times 40}{1.2 \times 2.95}=123.5 \leq 0.06 \times 3000=180 \mathrm{kPa} 。
\end{aligned}
$$

Compression calculation of cement-soil wall By formula:

$$
1.25 \gamma_{0} \gamma_{\mathrm{cs}} z+\frac{M}{W} \leq f_{\mathrm{cs}}
$$




$$
1.25 \times 1.0 \times 22 \times 8.5+\frac{6 \times M^{+}}{1 \times 2.95^{2}}=766.9 \leq 3000 \mathrm{kPa}
$$

The results show that the strength of the front wall can meet the design requirements of the tensile strength.

Cause analysis and measures of cracks. To find out the reasons that excavation and precipitation the posterior wall of soil produced a downward settlement, which not only result in the increase of cement soil pile bending moment, roof of confined concrete exacerbate this effect; $6 \sim 8$ $\mathrm{m}$ poor soil, cement soil strength insufficient (probably less than $2 \mathrm{MPa}$ ), causing cracking. Continue to carry out the next step of construction, not found a new crack.

The emergence of the oblique crack is related to the horizontal displacement of the wall, and the large wall horizontal displacement and the settlement of the middle part of the wall, so that the cement soil produced the shear crack.

\section{Conclusions}

This paper presents a theoretical method for calculating the cracking of the front wall of cement soil, and has been verified by the practical engineering.

Theoretical analysis and engineering practice show that the cracking of the concrete wall of the front wall is related to many factors, and the measures should be taken to reduce the stress level of the cement soil pile and avoid the tension stress.

More data should be monitored to deepen and enrich the theory of crack resistance design calculation.

It is suggested that the concrete surface layer and other reliable measures to improve the tensile strength of the front wall and solve the cracking problem of the front wall are improved by inserting the reinforcement and adjusting the cement soil pile.

\section{References}

[1] TONG Huai-feng, ZHOU Tong-he, GUO Yuan-cheng, LI Feng. Application of the compund pile wall supporting structure for deep excavation in soft region[C]// Proceedings of the 2006 National Conference by Foundation Branch of the China Architecture Society. Beijing: Intellectual Property Publishing House, 2006: 189-193. (in Chinese).

[2]GUO Yuan-cheng, WANG Kun, ZHOU Tong-he, WU Peng. Design-calculation method of single pile compound pile wall[J]. Journal of Zhengzhou University (Engneering Sciences), 2007,28(4): 68-72. (in Chinese).

[3]GUO Yuan-cheng, WU Peng, WANG Kun. Sensitivity analysis of the compound pile wall supporting structure[J]. Henan Science, 2008, 26(2): 204-207. (in Chinese).

[4]HUANG Qiang. Application manual of technical specification for retaining and protection of building foundation excavations[M]. Beijing: China Architecture and Building Press, 1999. (in Chinese).

[5]SHI Pei-dong, SUN Jun. Special techniques problem in deep excavation engineering[M]. Beijing: China Communications Press, 2004. (in Chinese). 